\title{
COMMENTS
}

\section{THE INEFFICIENCY OF THE NO-DUTY-TO-RESCUE RULE AND A PROPOSED "SIMILAR RISK" ALTERNATIVE}

\author{
ERICH. GRUSH† \\ INTRODUCTION
}

One of the most settled and basic common-law rules that all law students learn is that there is no general duty to rescue someone. Although there are many exceptions to this general rule,' the basic principle has been widely accepted. It is unclear, however, whether the rule is based on liberty or social-utility concerns. Perhaps common-law courts feared the undue interference with an individual's liberty that would result from imposing a seemingly limitless duty to rescue every person in danger. Alternatively, these courts might have felt that the costs of imposing liability for failure to rescue were generally greater than the benefits to be derived.

This Comment analyzes various efficiency ${ }^{2}$ arguments that have been presented in support of the "no duty" rule and proposes a new rule that promotes both efficiency and personal liberty. Specifically, the Comment addresses Professor William Landes and Judge Richard Posner's argument that the no-duty rule is efficient because potential rescuers will avoid rescue situations if a liability rule exists. ${ }^{3}$ For example, someone who swims well might avoid beaches where poor

† B.S. 1995, University of Michigan; J.D. Candidate 1998, University of Pennsylvania. This Comment is dedicated to my parents, Hank and Joyce Grush, who have provided me with support and encouragement throughout my education. I would like to thank Professor Reed Shuldiner, Suling Lam, Steven Chung, Stuart Rosenthal, and Susan McCabe Schupansky for their insightful suggestions.

'See infra notes 10-12 and accompanying text.

${ }^{2}$ For purposes of this Comment, a rule is efficient if its total societal benefit is greater than its total societal cost.

s See William M. Landes \& Richard A. Posner, Salvors, Finders, Good Samaritans, and Other Rescuers: An Economic Study of Law and Altruism, $7 \mathrm{~J}$. LEGAL STUD. 83, 119-21 (1978) (demonstrating that "liability may be less efficient than non-liability" in nonrescue situations). 
swimmers are known to swim. By questioning the assumptions behind Landes and Posner's economic model, and by extending their model, this Comment demonstrates that the no-duty rule is, in fact, socially inefficient, at least in some contexts.

Recognizing that the liability rule is sometimes efficient and sometimes inefficient, this Comment proposes a "similar risk" rule which better promotes efficiency. The similar-risk rule would impose liability for failure to rescue only if a potential rescuer is subject to a risk similar to the risk that the potential victim faces. If the potential rescuer is faced with a similar risk, she would benefit from a liability rule because she could also be a potential victim in need of the rule's protection at some point in the future. This rule is efficient because each person would benefit under the rule.

Part I summarizes the common-law no-duty-to-rescue rule and its exceptions. Part II analyzes the general efficiency argument against a liability rule and details Landes and Posner's argument that substitution of potential rescuers away from rescue situations may militate against the utility of a liability rule. ${ }^{5}$ Part III explains Professor Richard Hasen's response to the Landes-Posner model. Hasen argues that since potential rescuers may also be potential victims, they should favor a liability rule. ${ }^{6}$ Part IV extends Hasen's analysis to provide additional arguments for why the no-duty rule is inefficient. Recognizing that the no-duty and liability rules may each be inefficient in different contexts, Part V proposes the similar-risk rule discussed above. This Comment argues that the similar-risk rule satisfies both utility and liberty concerns in all contexts.

\section{THE COMMON-LAW NO-DUTY-TO-RESCUE RULE}

There is no affirmative duty to rescue another person who is in danger. ${ }^{7}$ In addition, there is no general duty to warn potential vic-

${ }^{4}$ See infra Part V.

${ }^{5}$ According to Landes and Posner, rescuer substitution away from potential victims would occur because rescuers would not want to be present in areas where they may be called upon to save a potential victim. See Landes \& Posner, supra note 3, at $119-21$.

${ }^{6}$ See Richard L. Hasen, The Efficient Duty to Rescue, 15 INT'L REV. L. \& EcON. 141, 147 (1995).

${ }_{7}^{7}$ See, e.g., Buch v. Amory Mfg. Co., 44 A. 809, 810-11 (N.H. 1898) (distinguishing between moral duties to act and affirmative legal duties to act), overruled in part on other grounds by Ouellette v. Blanchard, 364 A.2d 631 (N.H. 1976); RESTATEMENT (SECOND) OF TORTS $\S 314$ (1965) (stating that there is no general affirmative duty to act for another person's protection). 
tims of danger. ${ }^{8}$ There are, however, exceptions to this general rule which do impose liability for failure to rescue in some situations. For example, if there is a special relationship between the rescuer and the victim, such as that between a parent and a child, the rescuer may have an affirmative duty to rescue. ${ }^{9}$ Additionally, an affirmative duty exists to rescue someone who has fallen overboard while on the seas. ${ }^{10}$ Other exceptions include situations in which a potential rescuer already has voluntarily undertaken a rescue, ${ }^{11}$ or in which a potential rescuer creates the situation that puts the victim in danger. ${ }^{12}$

The policies that underlie these rules are not certain. Although these rules may be based on notions of justice, fairness, or liberty, they may also be explained on social efficiency and utility grounds. ${ }^{13}$ The next Part offers a general explanation for why the no-duty rule may be inefficient.

\section{IS TFE NO-DUTY-TO-RESCUE RULE EFFICIENT?}

The no-duty rule may be inefficient since it is applied even if the cost to the potential rescuer is trivial. Judge Learned Hand's wellknown "BPL" analysis ${ }^{14}$ demonstrates how inefficient the law may be: The burden $(B)$ to the potential rescuer can be slight; the loss to the potential victim $(L)$ is probably great; and the probability of the loss occurring $(P)$ can also be large. ${ }^{15}$ In other words, the harm to the po-

${ }^{8}$ See, e.g., Buch, $44 \mathrm{~A}$. at $810-11$ (stating the general common-law no-duty-to-warn rule).

${ }^{9}$ See, e.g., State v. Hunter, 911 P.2d 1121, 1124 (Kan. Ct. App. 1996) (holding that the defendant owed a duty to a gunshot victim because she was in his house and he "controlled access to her"). Such special relationships include "parent/child, employer/employee, common carrier/passenger, [and] innkeeper/guest." Id.

${ }^{10}$ See, e.g., Ricardo N., Inc. v. Turcios de Argueta, 907 S.W.2d 423, 426 (Tex. 1995) (recognizing a duty to rescue a sailor who fell overboard).

"See, e.g., Erie R.R. v. Stewart, 40 F.2d 855, 857 (6th Cir. 1930) (holding the railroad negligent because it discontinued a practice of having a watchman warn traffic); RESTATEMENT (SECOND) OF TORTS $§ 323$ (stating that a person is subject to liability for negligent performance of service voluntarily undertaken).

${ }_{12}$ See, e.g., Montgomery v. National Convoy \& Trucking Co., 195 S.E. 247, 251-53 (S.C. 1938) (upholding the trial court's judgment that the defendant was negligent in not removing, or giving warning of, a barrier imposed by the defendant on the highway); RESTATEMENT (SECOND) OF TORTS $\$ 322$ (setting forth the duty to aid persons harmed by one's own conduct).

13 See infra Part II.

14 See United States v. Carroll Towing Co., 159 F.2d 169, 173 (2d Cir. 1947) (using a "BPL" analysis to determine a boat owner's duty to protect against injuries).

${ }^{15}$ See RICHARD A. POSNER, ECONOMIC ANALYSIS OF THE LAW 189-91 (4th ed. 1992) (demonstrating how the no-duty rule leads to anomalous results). 
tential victim, discounted by the probability of the harm occurring, can outweigh the trivial cost to the potential rescuer. At a simplistic level, then, applying the no-duty rule can often contradict Judge Posner's argument that the common law is efficient. ${ }^{16}$

Landes and Posner argue that the common-law no-duty-to-rescue rule is efficient because potential rescuers will avoid areas in which potential victims reside if a liability rule is imposed. ${ }^{17}$ This substitution effect assumes that there are two nonoverlapping groups in society-potential victims and potential rescuers. ${ }^{18}$

Landes and Posner use a differential-equation model to explain this substitution effect. ${ }^{19}$ Their model assumes that there are two activities $(A$ and $B$ ) that a potential rescuer may choose. Activity $A$ is assumed to have potential victims, while activity $B$ is assumed to have no potential victims. Under a system that uses a liability rule, a potential rescuer would decide whether the potential cost of rescuing someone by staying in activity $A$ outweighs her loss in utility by switching to activity $B .^{20}$ If potential rescuers switch to activity $B$, then the liability rule would be ineffective-if there are no potential rescuers in activity $A$, then a potential victim, and thus society in general, would not gain from the rule. Additionally, by switching to activity $B$, a potential rescuer may lose utility. Since she chose activity $A$ without regard to the liability rule, it is fair to assume that she preferred activity $A$ to activity $B$. By switching to activity $B$, she engages in an activity that she would not normally choose.

For example, suppose Beth swims very well and prefers to go to Deep End Beach, a very popular place for tourists. Unfortunately, the tourists tend to swim poorly and frequently call on Beth to save them from drowning. Beth knows that if she does not save the tourists she

${ }^{16}$ See id. at 254-55 (questioning how the common law can "make as much economic sense as it seems to do").

${ }^{17}$ See Landes \& Posner, supra note 3, at 120. Landes and Posner's argument depends, as do many arguments in this Comment, on the assumption that enough information is available to potential rescuers and potential victims in deciding whether or not to substitute between activities.

${ }^{18}$ See id. at 119-20 (noting the nonoverlapping nature of the two societal groups). The validity of this assumption is crucial in deciding whether the no-duty-to-rescue rule is efficient. If a potential rescuer is also a potential victim, then she will not substitute away from rescue situations. See id. at 120.

${ }^{19}$ See id. at 119-24 (developing the differential-equation model).

${ }^{20}$ I assume, as do Landes and Posner, and Hasen, that people are rational. See, e.g., POSNER, supra note 15 , at $3-4$. Therefore, they make decisions to maximize expected outcomes of those decisions. This assumption lies behind most law-and-economics analysis, and analyzing it is beyond the scope of this Comment. 
may be liable to them under a liability rule. Instead of subjecting herself to potential liability, Beth decides to substitute to Seclusion Beach, a place where there are only locals who swim well. In this situation, the liability rule has created inefficiency because Beth loses utility from switching to a location she does not prefer.

\section{HASEN'S MODEL: A PERSON AS BOTH POTENTIAL RESCUER AND POTENTIAL VICTIM}

Professor Richard Hasen argues that the classes of potential victims and potential rescuers are overlapping. ${ }^{21}$ He claims, therefore, that potential rescuers will each gain utility under a liability rule since they receive value from the possibility of being rescued themselves. For example, pedestrian $A$ could warn pedestrian $B$ of a falling bowling ball, just as pedestrian $A$ could be warned about falling objects by pedestrian $B$ or someone else. In contrast, Landes and Posner implicitly assume that a potential rescuer receives no benefit from the imposition of a liability rule because the rescuer could not be a potential victim. ${ }^{22}$

Let $U$ be a person's utility independent of the rescue issue, $P$ be the probability that a person will be involved in a rescue situation (either as a potential rescuer or potential victim), $p_{1}$ be the probability that the person would be a victim (conditioned on the event that she is in a rescue situation), $V$ be the value that the person places on her own life, and $C$ be the cost of undertaking a rescue. Hasen argues that a person who could be either a rescuer or a victim will prefer a liability rule if: $U-P\left(1-p_{1}\right) C>U-P\left(p_{1}\right) V$, or when $p_{1}>C /(V+C)^{23}$

The idea behind Hasen's inequality can be demonstrated with an example. Suppose Beth, the beachgoer who swims well, has a 1\% chance of being in a rescue situation. Further, suppose Beth recog-

${ }^{23}$ See Hasen, supra note 6, at 142; cf. Landes \& Posner, supra note 3, at $120 \mathrm{n} .95$ (noting their model would be more complicated if the classes overlapped).

${ }^{22}$ See Landes \& Posner, supra note 3, at 120 (discussing the logical result of making victims and rescuers mutually exclusive groups).

${ }^{23}$ See Hasen, supra note 6, at 143 (explaining the conditions under which an individual would prefer a liability rule). The left side of the inequality represents the utility a person receives under the liability rule, while the right side is the utility a person receives under a no-liability rule. Hasen assumes that a rescuer will choose to pay the minimal cost of rescue rather than subject herself to liability. See id. He also assumes that individuals are risk-neutral. See id. at 142. Throughout this Comment, I make the same assumption of risk neutrality. However, to the extent that people are risk-averse, my argument is more valid because people will have an even greater preference for preserving their lives with a liability rule. 
nizes that if she is in a rescue situation, she will be a potential rescuer $80 \%$ of the time $\left(1-p_{1}=0.8\right)$, while $20 \%$ of the time she will be a potential victim because she is drowning $\left(p_{1}=0.2\right)$. Finally, suppose she values her life at $\$ 1,000,000$, but the cost of rescuing someone else is only $\$ 100$. Using Hasen's inequality, the amount she would lose under a liability rule is the $\$ 100$ cost of rescue, discounted by the probability that she will have to rescue someone ( $1 \% \times 80 \%$, or $0.8 \%)$. Under a liability rule, the cost per swimming excursion would be 80 cents $(\$ 100 \times 0.8 \%)$. In contrast, the amount she would lose under a no-duty rule is the $\$ 1,000,000$ value of her life, discounted by the probability that she would lose it $-1 \% \times 20 \%$, or $0.2 \%$. Under a noduty rule, Beth's cost per swim would be $\$ 2000$ ( $\$ 1,000,000 \times 0.2 \%$ ). Comparing Beth's per swim cost of 80 cents under a liability rule to her $\$ 2000$ per swim cost under a no-duty rule, Hasen's inequality demonstrates that Beth would prefer a liability rule.

Using the simplified inequality stated above, a person would prefer a liability rule if $p_{1}>C /(V+C)$. Analyzed under this simpler formula, Beth still prefers a liability rule because the probability that she would be a potential victim in a rescue situation $(20 \%)$ is greater than the ratio of the cost of rescue $(\$ 100)$ to the value of her life plus the cost of rescue $(\$ 1,000,000+\$ 100)$, or $0.001 \%$.

The previous example not only demonstrates how Hasen's inequality works; it also demonstrates that the conditions which favor a liability rule are often met. Since $C$, the cost of rescue, generally will be quite small in comparison to $V$, the value of the rescued potential victim's life, the right side of the simplified inequality should be close to zero, as in our example. Even if $V$ and $C$ are equal, ${ }^{24}$ the inequality may often be satisfied because $p_{1}$ need only be greater than $0.5^{25}$ to meet the condition for when a liability rule is efficient. Thus, as a general rule, society would prefer a liability rule since each individual would likely prefer it. ${ }^{26}$ If individuals prefer the security of the liabil-

${ }^{24}$ This condition would imply that a potential rescuer should expect to lose her life while attempting the rescue. Since we have assumed that $C$ is quite small, the assumption that $C$ and $V$ are equal is a much stronger condition than necessary to prove that the liability rule is efficient. Of course, $C$ may not be higher than $V$ or else the rescuer will not attempt the rescue.

${ }^{25} p_{1}$ will be greater than 0.5 if a person is more likely to be a victim than a rescuer.

${ }^{26}$ See Hasen, supra note 6, at $142-43$. It is possible, however, that society as a whole may be harmed by a rule that a majority of people prefer. That possibility depends on the value that each person places on having the rule. For example, if 100 people have an increased utility of $\$ 1$ from the rule, but one person loses $\$ 10,000$ from the rule, then the rule is harmful to society overall. In the case we have been considering, 
ity rule, they will not substitute to activity $B$ as Landes and Posner fear. In our example, since Beth prefers a liability rule, it will not change her decision of whether to go to Deep End Beach or Seclusion Beach. According to Hasen, then, a liability rule is efficient because Beth and others like her will be present to save victims. Later in this Comment, I propose a rule that recognizes that Hasen is correct about the liability rule's efficiency in some instances, while Landes and Posner are correct about its inefficiency in others. My proposed rule imposes liability when Hasen is correct, but not when Landes and Posner are correct.

\section{ADDITIONAL ARGUMENTS THAT THE NO-DUTY-TO-RESCUE RULE IS INEFFICIENT}

As explained previously, imposition of a liability rule may be efficient because potential rescuers also can be potential victims. Thus, substitution should not occur based on the existence of the liability rule alone. Even if Landes and Posner assume correctly that the two groups are nonoverlapping, rescuer substitution still might not defeat the efficiency of a liability rule for two reasons. First, not every potential rescuer will substitute away from potential victims. Second, potential victims also may substitute to the activity which potential rescuers choose. Additionally, I argue that the liability rule is more efficient than the no-duty rule even when a rescuer must take on high risks in rescuing the victim.

\section{A. Enough Potential Rescuers May Stay in Activity A to Allow for Rescues}

Even if we accept Landes and Posner's assumption that potential rescuers and potential victims are nonoverlapping groups, substitution still might not defeat the efficiency of a liability rule. This is because enough potential rescuers may remain in activity $A$ to provide a benefit to potential victims. ${ }^{27}$ When Landes and Posner claim that

though, it is likely that people who prefer the rule will value the rule highly since their lives are at stake.

${ }^{27}$ Cf. Ian Ayres, A Theoretical Fox Meets Empirical Hedgehogs: Competing Approaches to Accident Economics, 82 Nw. U. L. REV. 837, 841 (1988) (reviewing WILIIAM M. LANDES \& RICHARD A. POSNER, THE ECONOMIC STRUCTURE OF TORT LAW (1987), and STEVEN SHAVELL, ECONOMIC ANALYSIS OF ACCIDENT LAW (1987)) (noting that the "possibility of rescue (albeit with ex ante substitution) under the liability rule" is "bigger than" the "zero-rescue equilibrium under the no-liability rule"). Ayres does not consider the possibility that the loss of utility to potential rescuers in switching between activities 
some potential rescuers will switch activities, they implicitly admit that some will not. ${ }^{28}$ The amount of substitution will depend on how many potential rescuers favor avoiding rescue costs at the expense of utility lost by switching activities. Assuming that the cost of rescue is slight compared to the benefit of rescue, substitution should not destroy the utility of a liability rule. This is true since the loss of utility to potential rescuers in switching between activities should not outweigh the benefit of saving even a small number of people from death.

Let $D$ be the loss in utility to each individual who substitutes to activity $B .^{29}$ Also, let $P_{1}$ be the probability that a potential rescuer would be faced with a rescue situation in activity $A$. $C$ is the cost of rescue. A potential rescuer will not switch activities unless her loss in utility from substitution is less than her expected cost of rescue, or unless $D<P, C$.

For example, assume that: Beth the beachgoer would lose $\$ 100$ of utility by switching beaches; the probability of a rescue situation occurring at Deep End Beach is 20\%; and Beth's cost of rescue is $\$ 100$. In this situation, Beth would not substitute between activities because her loss from switching $(\$ 100)$ is greater than her expected cost of rescue ( $\$ 100 \times 20 \%$, or $\$ 20)$.

For each potential rescuer who does not substitute, the expected gain to society will be $P_{1} V$ because $P_{1}$ is the probability of a rescuer being in a rescue situation and $V$ is the value of each life saved. ${ }^{30}$ Let $X$ be the proportion of potential rescuers who substitute. Then $1-X$ is the proportion who do not. A liability rule is inefficient relative to the no-duty rule only if its costs outweigh its benefits, or if $\mathrm{XD}>(1-X) P_{1} V$. Using the assumption that $D<P_{1} C$ (that the loss of

may outweigh the benefit to rescued victims.

${ }^{28}$ See Landes \& Posner, supra note 3, at 121.

29 This example relies on the clearly false assumption that $D$ is the same for all potential rescuers. If, however, $D$ is the average loss of utility for potential rescuers, the calculations will hold true for a substantial number of potential rescuers. The larger the variance of $D$, the less accurate the calculations will be.

${ }^{30}$ This result assumes that only one rescuer is present in any given rescue situation. It is arguable that the subsequent conclusions are invalid if there are more potential rescuers available. Such an argument fails for two reasons. First, the difference between the number of potential rescuers and victims in a rescue situation may be outweighed by the large value of $V$ in the derived inequalities. Second, as the number of potential rescuers increases, the expected cost of rescue $\left(P_{1} C\right)$ for each decreases because it becomes less likely that any one rescuer will be involved. As this expected cost decreases, and the lost utility from substitution remains constant, a potential rescuer becomes less likely to substitute. 
utility from substitution is less than the expected cost of rescue), a liability rule is inefficient only if $X P_{1} C>(1-X) P_{1} V$, which can be simplified as $X>V /(C+V)$.

I have assumed that $C$ is trivial in comparison to $V$. As a result, the right side of the inequality is close to one in many situations. Therefore, the proportion of potential rescuers who substitute activities must be almost $100 \%$ before Landes and Posner's argument would defeat the justification for a liability rule. For example, let the cost to a rescuer for warning a pedestrian of a falling bowling ball be $\$ 1000$. Assume that the pedestrian values her life at $\$ 1,000,000$. The inequality condition becomes $X>99.9 \%$. Therefore, more than $99.9 \%$ of potential rescuers would need to substitute away from potential victims to make a liability rule inefficient.

This analysis demonstrates that the loss of utility to potential rescuers from substitution may be outweighed by the gain in value from lives saved even when very few rescuers choose not to substitute. For example, Beth the beachgoer may be the only potential rescuer to stay with potential victims at Deep End Beach. The 100 other potential rescuers may substitute to Seclusion Beach, where there are no potential victims. The substituting potential rescuers each may lose $\$ 10$ of utility by substituting, for a net loss of $\$ 1000$ (100 rescuers multiplied by $\$ 10$ lost utility per rescuer). Additionally, there would be a rescue cost-suppose it is $\$ 1000$. If, however, Beth has even a $1 \%$ chance of saving a life at Deep End Beach, and that life is worth $\$ 1,000,000$, then the expected benefit to society is $\$ 10,000$, thus justifying the $\$ 2000$ net cost to society. ${ }^{31}$

\section{B. The Costs of Changing Between Activities May Prevent Substitution}

Transaction costs may preserve the efficiency of a liability rule by preventing substitution. Such transaction costs may be very real in rescue situations: a person may have to change employment or move to a new city, for example, to switch between activities; or, perhaps someone would have to switch membership at a gym, requiring a down payment. These substitutions could entail substantial transac-

${ }^{31}$ This analysis may be less persuasive if a potential rescuer's probability of being in a rescue situation increases when the other potential rescuers leave the beach. For example, a rescuer may be more likely to observe a baby face-down in a puddle if she is on a deserted street rather than a crowded street. One can think of examples where this is not true, however: Beth's chances of seeing a drowning swimmer should be independent of the number of rescuers on a beach. 
tion costs which might lead a potential rescuer to stay in her current activity.

These transaction costs are separate from the cost of the loss of utility from substitution that was discussed in the last section. Losses in utility are continuous, such as the loss in utility from swimming in a polluted lake. The transaction costs, however, are one-time costs, such as moving to a new city. These one-time costs may prevent substitution even if the potential rescuer would gain utility by switching activities because people often weigh one-time, up-front costs more heavily than long-term gains. ${ }^{32}$

\section{Potential Victim Substitution May Prevent the Effects of Potential Rescuer Substitution}

The model developed by Landes and Posner implicitly assumes that potential victims are immobile. They do not explain, however, why this assumption is valid. It seems that if potential rescuers may substitute to a new area, then potential victims may do so as well. ${ }^{33} \mathrm{~A}$ simple analysis demonstrates the reasonable likelihood of potential victim substitution.

Let $P_{2}$ be the probability of a potential victim being in a rescue situation in activity $A$. Let $U$ be his utility if he switches to activity $B$. Assuming that all potential rescuers substitute to activity $B,{ }^{34}$ a potential victim will have a utility of $U-P_{2} V$ if he chooses to stay in activity $A^{35}$ Therefore, the potential victim will switch to activity $B$ if $U-P_{2} V<U^{36}$ Assuming a potential victim places a nonzero value on his life, the potential victim will always choose to substitute.

${ }^{32}$ This is true because of psychology and "shallow pockets": People are more willing and able to make small payments over time than to make large, one-time payments. For example, few people are willing or able to buy a house with cash because the one-time cost is so large.

${ }^{3 s}$ This assumes that potential victims know where potential rescuers substitute. Victim substitution is less likely to occur when there is asymmetrical information about activities between potential rescuers and potential victims.

${ }^{34}$ This assumption probably is too strong. See supra Part IV.A-B.

${ }^{35}$ This is so because $P_{2} V$ is the opportunity cost of not substituting to the new activity. By not substituting, a potential victim's utility is reduced from $U$ to $U-P_{2} V$.

${ }^{36}$ Potential victims may also face loss of utility from switching activities. As argued below, however, potential victims value substitution more than potential rescuers. If potential rescuers substitute despite the value of $D$ (the loss in utility from substituting) so should potential victims. This would not be true if $D$ is higher for potential victims than potential rescuers. For example, activity $B$ may be more hazardous than activity $A$, so that a potential victim would be more negatively affected than a potential rescuer. 
Additionally, if we assume that the value of a potential victim's life is substantially larger than the cost of rescue, then the potential victim's gain in utility from substitution will almost always exceed that of the potential rescuer - the potential victim stands to gain his life, while the potential rescuer stands only to avoid the cost of rescue. By substituting, the potential victim generates a surplus (utility gain) of $P_{2} V$ (the value of his saved life discounted by the probability of losing it). At the same time, the potential rescuer avoids a loss of $P_{1} C$ (the cost of rescue discounted by the probability of encountering a rescue situation) through substitution.

The potential victim will value switching activities more than the potential rescuer if the expected benefit of a potential victim's life being saved is greater than the expected cost of rescue, or if $P_{2} V>P_{1} C$. This condition is almost always satisfied if we assume that $P_{1}$ and $P_{2}$ are nearly equivalent, that is, if potential rescuers and potential victims have roughly equal chance of being in a rescue situation. Even if $P_{1}$ is substantially larger than $P_{2}$, the condition probably still will be satisfied since the value of the potential victim's life is so much larger than the trivial cost of rescue. ${ }^{37}$ The potential victim, therefore, will place a higher value on substitution than the potential rescuer.

For example, suppose Rukesh, who has a black belt in karate, is tired of saving people's lives during his walk home on Chestnut Street. He is considering substituting away from Chestnut Street so that he can avoid the $\$ 100$ cost of rescue each time his services are needed. Rukesh has to save someone $10 \%$ of the time, for an average cost of $\$ 10$ ( $\$ 100 \times 10 \%$ ) per trip home on Chestnut. The potential victims, however, value their lives at $\$ 1,000,000$ each. If they each have a $10 \%$ chance of being a victim each time they walk home, then they value substitution to the street Rukesh travels at $\$ 100,000$ $(\$ 1,000,000 \times 10 \%)$. Therefore, potential victims will substitute to follow potential rescuers like Rukesh. ${ }^{38}$

Assuming that there are transaction costs involved in substituting activities, the group with the strongest incentive to substitute will

${ }^{37}$ For example, if $P_{1}$ is $0.5, P_{2}$ is $0.01, V$ (value of life) is $\$ 1,000,000$, and $C$ (cost of rescue) is $\$ 100$, the inequality becomes $\$ 10,000>\$ 50$. This demonstrates the powerful incentive for potential victim substitution.

${ }^{39}$ Landes and Posner, by arguing that victims and potential rescuers are nonoverlapping groups, assume that people are either inherently rescuers or inherently victims. See Landes \& Posner, supra note 3, at $120 \mathrm{n} .95$ (assuming that a person is "either a nonvictim or a victim but not a member of both classes"); see also supra note 18 and accompanying text. Therefore, a victim's status as victim will not change by substituting activities. 
make the final substitution in equilibrium. Suppose Rukesh chooses to substitute away from a potential victim, expecting to save $\$ 100$, as in the previous example. A potential victim also chooses to substitute to where Rukesh is because it increases her utility by $\$ 100,000$, as in the previous example. They will continue to substitute away from each other because each gains utility from substituting if there are no transaction costs. However, if each substitution costs each of them $\$ 10$ in transaction costs, then Rukesh will not want to substitute more than ten times, because he will have wasted his $\$ 100$ surplus. The potential victim, on the other hand, would have $\$ 99,900$ of surplus left after substituting ten times at a cost of $\$ 10$. Consequently, potential rescuers may not be able to substitute away from potential victims who have less to lose relative to their gain than do potential rescuers.

The above discussion suggests that substitution is an ongoing, multiparty process. As a result of this flux, it is likely that at any given time some potential rescuers and potential victims will be in one area, and some of each will be in another. Since individual potential rescuers have differing cost-benefit ratios, they will not all make the same decision at the same time. Even if only some potential rescuers substitute, however, a liability rule probably would still be efficient. If half of the potential rescuers substitute away from an activity to avoid liability, the other half will remain in the original activity to save the lives of potential victims. ${ }^{39}$

It could be argued that the costs of substitution will waste any possible surplus generated from a liability rule. Each potential victim and potential rescuer is willing to pay up to $P_{2} V$ and $P_{1} C$, respectively (the amount of benefit they receive from substituting). The surplus from these benefits, however, may be consumed by substitution costs. This situation is likely to occur in tort cases because parties often cannot contract ahead of time to avoid unnecessary spending. ${ }^{40}$

There are two reasons, however, why substitution costs might not consume substitution surplus. First, since the potential victim's surplus is so much greater than the potential rescuer's surplus, the potential victim may still have substitution surplus left over after the potential rescuer has eliminated her substitution surplus. This assumes

${ }^{39}$ See Ayres, supra note 27, at 841 (observing that there always will be more rescues in a liability regime, even with substitution, than the "zero-rescue equilibrium under the no-liability rule").

${ }^{40}$ See, e.g., POSNER, supra note 15, at 163-64 (explaining that prohibitive transaction costs prevent ex ante contracts between two automobile drivers involved in an accident). 
that the potential victim's surplus $\left(P_{2} V\right)$ is much greater than the cost which the potential rescuer wishes to avoid $\left(P_{1} C\right){ }^{41}$ For example, Rukesh, the potential rescuer/karate expert, expects a cost of rescue which is less than the potential victim's expected benefit from being saved. As before, this assumption appears valid in some contexts. ${ }^{42}$

If $N_{1}$ is the number of potential rescuers and $N_{2}$ is the number of potential victims, the net gain to society would be $N_{2} P_{2} V-N_{1} P_{1} C$. Assuming that $P_{2}$ and $P_{1}$ are roughly equal (let that value be $P$ ), and assuming that $N_{2}$ and $N_{1}$ are also roughly equal (let that value be $N$ ), the net social gain is $N P(V-C)$, which is positive assuming that the value of $C$ is less than $V$. Thus, the liability rule would be more efficient than the no-duty rule in these circumstances because it results in a net social gain to society.

The assumptions that $N_{1}$ and $N_{2}$, and $P_{1}$ and $P_{2}$, are roughly equal may be untrue. For example, there may be ten times as many potential rescuers as potential victims. The net gain to society may still be positive, however, since $V$ is assumed to be vastly larger than $C^{43}$ This is an empirical question which will depend on the context. For example, a victim injured in an automobile accident on a crowded street may have many potential rescuers. In contrast, someone injured while playing tennis on an isolated tennis court may have only one potential rescuer-his opponent.

The second reason why substitution costs might not swallow the surplus generated by a liability rule is that potential rescuers may realize the futility in running away from potential victims who follow them. If so, the potential rescuers may not substitute at all.

The argument above assumes that the potential rescuer has enough information to know that she will lose the war of substitution. The assumption seems rational-a potential rescuer should recognize

${ }^{11}$ More precisely, this assumes that $P_{2} V$ is at least twice as large as $P_{1} C . P_{1} C$ is an upper bound on the amount that both a potential rescuer and a potential victim will spend on transaction costs before reaching equilibrium because a potential victim will not need to spend more than the highest amount that a potential rescuer will spend. (The potential rescuer will not move after spending $P_{l} C$.) Therefore, the total transaction costs of both parties together will be no more than $2\left(P_{1} C\right)$. The net benefit to society, then, is the surplus of the potential victim, less the total transaction costs, or $\left(P_{2} V\right)-2\left(P_{1} C\right)$. If $\left(P_{2} V\right)-2\left(P_{1} C\right)$ is larger than zero, then, some of the potential victim's surplus will not be wasted by transaction costs.

${ }^{42}$ See supra notes 24-26 and accompanying text.

${ }^{43}$ For example, if the ratios of $N_{1}$ to $N_{2}$ and $P_{1}$ to $P_{2}$ are each 10 (10 potential rescuers to every one potential victim and the likelihood that for every one potential victim in a rescue situation there will be 10 potential rescuers also in a rescue situation), but $V$ is $\$ 1,000,000$ and $C$ is $\$ 100$, there is still a positive gain to society. 
that a potential victim values his life much more than the potential rescuer values her cost of rescue. This should lead the potential rescuer to conclude that a potential victim will substitute whenever a potential rescuer does. Consequently, she would not bother to incur substitution costs. In certain contexts, however, a potential rescuer may not perceive: (1) that a potential victim will value substitution; (2) that a potential victim will realize he can substitute; and (3) that a potential victim will realize where the rescuer has gone. In these situations, a potential rescuer may substitute even though it will be futile. Additionally, a potential victim will not be able to substitute correctly. Thus, in these contexts, Landes and Posner's assumption that rescuers will substitute away from victims ${ }^{44}$ would be correct. Nevertheless, if information availability is not a problem, then potential victims will substitute to activities in which potential rescuers participate. This result undermines Landes and Posner's concern that potential rescuer substitution will defeat the efficiency of a liability rule.

\section{The Common Law May Still Be Inefficient When There Is a Substantial Risk to the Life of a Rescuer}

To this point, I have assumed that the potential value of the victim's life is much greater than the cost of rescue. The liability rule may still be efficient even when the risk of harm to a potential rescuer is significant. If we assume that most people can be both potential rescuers and potential victims, then potential rescuers should prefer the liability rule despite potential substantial costs incident to a rescue because they could gain an even more substantial benefit-having their own life saved.

For example, assume Alice approaches Bill, who needs help removing a boulder that has fallen on him. Before seeing Bill, however, Alice just as easily could have been a potential victim as she could have been a potential rescuer. Therefore, in the abstract, before approaching Bill, Alice would prefer a liability rule if it helps potential victims more than it harms potential rescuers. Assuming that the probability of Alice saving Bill is greater than the probability of Alice being harmed, it would be socially beneficial for Alice to rescue Bill. Therefore, in the abstract, Alice generally would prefer a liability rule.

\footnotetext{
${ }^{41}$ See supra note 17 and accompanying text.
} 
This analytical explanation can be demonstrated using a variation of the inequality developed by Hasen. ${ }^{45}$ First, assume that there is a risk of death $\left(p_{2}\right)$ to a person acting as a rescuer. Also assume that this risk is independent of the risk of other costs $(C)$ associated with the rescue. The expected cost of a potential rescuer's loss of life $\left(p_{2} V\right)$ can be added to the trivial costs of rescue $(C)$ in Hasen's model. Thus, a person would prefer a liability rule to a no-duty rule whenever $U-P\left(1-p_{1}\right)\left(C+p_{2} V\right)>U-P\left(p_{1}\right)(V),{ }^{46}$ or when $p_{1}>\left(C+p_{2} V\right) /$ $\left(C+p_{2} V+V\right)$.

Assuming that $C$ is still trivial compared to $V$, the $C$ term would not significantly affect this inequality. ${ }^{47}$ Therefore, this relation is approximated by $p_{1}>p_{2} V /\left(p_{2} V+V\right)$, or $p_{1}>p_{2} /\left(p_{2}+1\right)$, or $p_{2}<p_{1}+p_{1} p_{2}$. An even stronger condition is $p_{2}<p_{1}$. In other words, we would prefer a liability rule if it is more probable that we would be a potential victim in a rescue situation than that we would lose our life while acting as a rescuer. This seems to be a condition which would hold true in a majority of cases. The average person probably has the same chance of being a rescuer as being a victim. Since there is most likely only one rescuer and one victim in each rescue situation, $p_{1}$ should be approximately 0.5 . The value of $p_{2}$ (the probability of a rescuer dying in a rescue situation) is probably not more than 0.5 because a rescuer in most situations will not risk her life. This question is, of course, an empirical one. It seems logical, however, that it is more likely that someone would be called upon to warn another person of a danger or to throw someone a life preserver, rather than to roll a boulder off a person's back.

My argument thus far should at least raise doubts about the theory that the no-duty rule is efficient in most contexts. Although there are some situations in which the no-duty rule is more efficient, there are others in which the liability rule is more efficient. My suggestions of numerical examples are not meant to prove that the liability rule is always more efficient than the no-duty rule, just that it is often more efficient. I propose a rule in the next Part to insure that the liability

${ }^{45}$ See supra Part III.

${ }^{16}$ See supra note 23 and accompanying text. This inequality modifies Hasen's inequality by subtracting from the utility of the liability rule the additional expected cost of a potential rescuer being killed in a rescue attempt.

${ }^{17}$ For example, suppose that the cost of throwing a drowning person a rope is $\$ 10$, and the value of the person's life is $\$ 1,000,000$. No matter what $p_{2}$ is, $C$ will have almost no effect on the right hand side of the second inequality condition. 
rule is applied in the appropriate contexts, and not when the no-duty rule may be more efficient.

\section{Proposal For a "Similar Risk" LIABILITy RULE TO PROMOte EFFICIENCY AND LIBERTY}

As explained throughout this Comment, Landes and Posner's fear that a liability rule would be inefficient is unfounded in many situations. ${ }^{48}$ It is difficult to understand why the common law would develop a rule that is inefficient. ${ }^{49}$

Hasen suggests that the liability rule may have been rejected not on the basis of efficiency grounds, but rather because of personal liberty concerns. ${ }^{50}$ Another scholar, john Kleinig, explains that the "no duty" rule is based on "the fear that Good Samaritan legislation will substantially diminish freedom. In a culture steeped in individualism, nothing produces more hysteria than measures which encroach on individual liberty .... [I] t constitutes an important thread within the Anglo-American sociomoral fabric." ${ }^{51}$ It is possible that concerns for personal liberty distorted common-law judges' efficiency intuitions. These concerns may have also served as a strong enough force to defeat numerous challenges to inefficient laws. The common-law rule that a person has no duty to rescue may, therefore, have nothing at all to do with efficiency. In constructing a new rule, it would be wise to strike a balance between personal liberty and efficiency concerns. I propose a rule that would do just that.

To ensure the rule's efficiency, the Landes-Posner and Hasen models must be reconciled with respect to their assumptions about whether potential rescuers and potential victims are mutually exclusive groups. ${ }^{52}$ In some contexts the Landes-Posner assumption of nonoverlapping groups is probably valid, while in other contexts

48 See supra Parts III-IV (discussing Hasen's model and additional arguments sustaining the efficiency of a liability rule).

19 See Robert CoOter \& ThOMAS Ulen, LAW ANd ECONOMics 376 (2d ed. 1997) (arguing that inefficient laws are more often challenged and, thus, more often overturned); Landes \& Posner, supra note 3, at $254-55$ (arguing that efficiency is a societal goal which courts can pursue, and that justice is based on efficiency).

${ }^{30}$ See Hasen, supra note 6, at 146 (noting that "society may have failed to demand a liability rule because the rule's infringement on personal liberty" is a large additional cost).

${ }^{51}$ John Kleinig, Good Samaritanism, 5 PHIL. \& PUB. AFF. 382, 403 (1976).

${ }^{32}$ Compare supra Part II (discussing the Landes-Posner view), with supra Part III (discussing the Hasen model). 
Hasen's assumption of overlapping groups holds true. ${ }^{53}$ It is unclear, however, which of these situations occurs more often.

Consider a situation where a landowner could rescue a trespasser by warning him of dangerous machinery on her property. Compare the likelihood of this situation to its converse, where the landowner is a potential victim of dangerous machinery on her own property and the trespasser is the potential rescuer. Logic dictates that the latter situation is less probable since the landowner is more familiar with the risks within her own property. Therefore, since the landowner is not likely to be a potential victim, and the trespasser is not likely to be a potential rescuer, the Landes-Posner assumption applies.

In contrast, consider the situation of a sailor on a ship at sea. All else being equal, the sailor is just as likely to be a potential rescuer (if a fellow shipmate falls overboard) as a potential victim (if she falls overboard). This example demonstrates that the Landes-Posner theory is sometimes wrong, and that Hasen's assumption applies in some circumstances.

Despite the apparent conflict between the Landes-Posner and Hasen assumptions, an approach that encompasses both broad scenarios can be developed. To do so, a "similar risk" rule could be constructed such that a potential rescuer would be held liable for failure to rescue if she is generally subject to a risk similar to the risk faced by the victim. A potential rescuer would be considered subject to the same risk faced by the victim if she could have been subject to the same risk at any point in time.

Such a rule would create efficient results under both assumptions. When Hasen's "overlapping risks" assumption is correct, so that the potential rescuer would herself prefer a liability rule in the abstract, then a liability rule is imposed on her. When Landes and Posner's exclusivity assumption is correct, so that the potential rescuer would not prefer a liability rule, even in the abstract, then liability is not imposed on her.

For example, the sailors in the previous hypothetical would have a duty to save each other because they would each value the liability rule over the no-duty rule before any rescue situation has arisen. The landowner mentioned above, however, would not owe the trespasser a rescue duty, because even in the abstract, the landowner would not prefer that landowners be liable to trespassers. The sailors are subject

${ }^{3 s}$ See supra Part III (comparing contexts in which assumptions of overlapping groups hold true). 
to similar risks, while the landowner is not subject to the same risk as a trespasser on her property.

Caselaw addressing both the landowner and sailor situations offers some support for the result that this proposed similar-risk rule suggests-the sailor has a duty to rescue and the landowner does not. ${ }^{54}$ There are numerous other contexts, however, where a potential rescuer fails to save a similarly situated victim and is not held liable. ${ }^{55}$ Thus, it appears that maritime law, which imposes a duty to rescue, provides an exception to the predominant common-law rule. ${ }^{56}$

One practical problem with the similar-risk rule is that its application depends on how broadly the risk to the potential victim is defined. For example, if the risk to the sailor is defined as being specific to her personal job of climbing a mast to adjust sails, her legal duty to rescue would extend no further than to those sailors with the same job. Alternatively, the risk to the sailor could be broadly defined to encompass the general risks associated with proximity to water, so that her duty to rescue would extend to any person near her. An infinite number of levels of specificity could be used to define risk, each changing the scope of the sailor's duty to rescue. In applying the proposed similar-risk rule, however, we may be able to trust judges to pick the right level of specificity to produce efficient outcomes. Posner himself believes that judges have a knack for correctly applying rules to attain efficiency. ${ }^{57}$

Moreover, if the risk can be defined appropriately, a similar-risk rule would satisfy the substitution concerns of Landes and Posner because persons subject to liability under the rule would not have an incentive to substitute. Indeed, as the condition proofs that follow will

${ }^{54}$ See Buch v. Amory Mfg. Co., 44 A. 809, 810-11 (N.H. 1898) (holding that a landowner did not have a legal duty to warn a trespassing child of dangerous machinery), overruled in part on other grounds by Ouellette v. Blanchard, 364 A.2d 631 (N.H. 1976); Ricardo N., Inc. v. Turcios de Argueta, 907 S.W.2d 423, 426 (Tex. 1995) (holding that a sailor's duty to rescue a man who had fallen overboard began as soon as the person had fallen); see also RESTATEMENT (SECOND) OF TORTS $\$ 333$ (1965) (stating the general rule that landowners have no duty of reasonable care toward trespassers).

${ }^{55}$ See, e.g., Yania v. Bigan, 155 A.2d 343, 346 (Pa. 1959) (refusing to hold a strip miner liable for not saving another strip miner from drowning); POSNER, supra note 15 , at 189-90 (noting that a pedestrian has no duty to save another pedestrian from a falling flower pot, and a swimmer has no duty to save another swimmer from drowning).

${ }_{56}$ See supra notes 7-10 and accompanying text.

${ }^{57}$ See POSNER, supra note 15, at 25455 (noting that although the "articulation [of common-law doctrines] in economic terms is beyond the capacity of most judges and lawyers, ... their intuition is not"). 
demonstrate, someone who is subject to liability under the rule also derives protection from the rule and, thus, would not substitute away from this protection.

The similar-risk rule can be defined with reference to Hasen's condition for when an individual would prefer a liability rule. When the individual is subject to a risk similar enough to that of the potential victim, she will generally favor the imposition of a liability rule (although not with respect to the specific rescue situation at hand). ${ }^{58}$ As discussed under Hasen's model, this condition is met when $p_{1}>C /(V+C)$, where $p_{1}$ represents the potential rescuer's probability of being subjected to a similar harm, $V$ is the value of her own life, and $C$ is the cost of rescuing someone from the harm. ${ }^{59}$

As previously discussed, this rule is pareto efficient ${ }^{60}$ because when this condition is met, every individual to which the condition applies would prefer a liability rule. ${ }^{61}$ Hence, before the accident occurs, the potential rescuer favors the rule if the condition is met. As a result, the rule will only impose legal duties on those people who value the liability rule more than the no-duty rule for the specific risk at issue. Additionally, if we assume that accidents are independent of each other, the potential rescuer's calculation of the above condition will not change after having liability imposed. ${ }^{62}$ She will, therefore, value the liability rule more than the no-duty rule at all times, whether before or after the imposition of liability.

The similar-risk rule not only satisfies efficiency concerns, but it also preserves individual liberty. If a legal duty is imposed only upon individuals who would voluntarily choose it, then there is less concern with compelling these individuals to rescue someone else. Indeed, only those individuals who do not favor a liability rule may raise liberty objections to the imposition of a duty. These persons, however, are exactly the individuals whom the rule exempts from liability.

${ }^{3 s}$ In the abstract, before realizing that she must rescue someone else, the potential rescuer would prefer a liability rule if she faces a risk similar to the one that eventually befalls the victim she is called upon to rescue. She may no longer prefer the liability rule in the specific instance when she is required to rescue a victim, but that does not change the fact that she values the rule in the abstract.

${ }^{39}$ See supra note 23 and accompanying text.

${ }^{60}$ Something is pareto efficient if it makes someone better off and no one worse off. See POSNER, supra note 15 , at 13.

'See supra notes 23-24 and accompanying text.

${ }^{62}$ Cf. supra note 58. 


\section{CONCLUSION}

Recognizing the potential inefficiency of the no-duty and liability rules and the possible liberty constraints inherent in a liability rule, this Comment proposes a "similar risk" rule. This rule would impose liability on a potential rescuer only if she faces risks similar to the potential victim. Since each person subject to the rule would benefit from it, the rule's application would be efficient. It would be efficient in the strictest sense because every person would, ex ante, expect to benefit from the rule-even if in some specific instances a rescuer may be worse off. By virtue of the rule's mathematical conditions, a person can only be liable if she generally expects to be better off under the liability rule.

Finally, the proposed similar-risk rule comports with liberty considerations because the potential rescuer would, in the abstract, choose the liability rule if given the chance. The individuals whose liberty we should fear restricting-those who oppose a liability rulewould not have a duty to rescue because they would never face a risk similar to the potential victim. Consequently, the similar-risk rule serves the dual purpose of protecting individual liberty and promoting social efficiency, thus solving major problems inherent in both the liability and no-duty rules. 